\title{
Microstructural Evolution and Pressure-Assisted Master Sintering Surface of Silicon Nitride
}

\author{
Kyong Jun An, Hyun Jong Kim and Myung Keun Han \\ Korea Institute of Industrial Technology, Songdo-Dong 7-47, Yonsoo-Gu, Incheon, 406-130, Korea
}

\begin{abstract}
The pressure-assisted master sintering surface (PMSS) of silicon nitride has been constructed, in which the sintered density during hot pressing can be predicted as a function of the integral of a temperature function over time at a given pressure, irrespective of the heating path. High-purity $\alpha-\mathrm{Si}_{3} \mathrm{~N}_{4}$ powder with the additives of $6.25 \% \mathrm{Y}_{2} \mathrm{O}_{3}$ and $1 \% \mathrm{Al}_{2} \mathrm{O}_{3}$ was used for this research. Densifications of silicon nitride were continuously recorded during heating at two different ramping rates of $0.083^{\circ} \mathrm{C} / \mathrm{s}$ and $0.167^{\circ} \mathrm{C} / \mathrm{s}$ up to $1800^{\circ} \mathrm{C}$ at fixed pressures from 7 to $34 \mathrm{MPa}$. The activation energy was estimated as $698 \mathrm{~kJ} / \mathrm{mol}$. During the hot pressing, the microstructural evolution of $\alpha$-Si $\mathrm{N}_{4}$ to $\beta$-phase $\mathrm{known}$ as a solid/liquid/solid mechanism was also observed. Using the PMSS of silicon nitride, the final density can be predicted to about $1 \%$ accuracy for a fixed pressure and an arbitrary temperature-time path. [doi:10.2320/matertrans.MRP2008026]
\end{abstract}

(Received January 18, 2008; Accepted June 3, 2008; Published July 16, 2008)

Keywords: silicon nitride, pressure-assisted master sintering surface, activation energy, hot pressing

\section{Introduction}

Silicon nitride, being a covalently bonded ceramics of low self-diffusion coefficients, can be densified by using high sintering temperature and/or high pressures to promote diffusion or activate deformation processes. Thereby, in most cases, small amounts of oxides are used as sintering aids typically $\mathrm{MgO}, \mathrm{Al}_{2} \mathrm{O}_{3}$ and $\mathrm{Y}_{2} \mathrm{O}_{3}$ to enhance densification of silicon nitride.

It has been demonstrated ${ }^{1,2)}$ that in order to fabricate highstrength, hot pressed $\mathrm{Si}_{3} \mathrm{~N}_{4}$, it is preferable to start with a powder that contains a high percentage of $\alpha-\mathrm{Si}_{3} \mathrm{~N}_{4}$. During hot pressing at temperatures above $1500^{\circ} \mathrm{C}$, the $\alpha$-phase transforms to the $\beta$-phase via a solid/liquid/solid mechanism. The mechanisms influencing the densification of $\mathrm{Si}_{3} \mathrm{~N}_{4}$ are known to be divided into three regions: the formation of a liquid phase; the $\alpha$ to $\beta$ transformation; and the Ostwald ripening or growth of the $\beta$ grains. ${ }^{1)} \mathrm{S}$. M. Wiederhorn et al. ${ }^{3)}$ studied the strength of $\mathrm{Y}_{2} \mathrm{O}_{3}$-doped hot-pressed silicon nitride as a function of temperature, time and applied pressure. They found the behavior of $\mathrm{Y}_{2} \mathrm{O}_{3}$-doped hot-pressed silicon nitride is superior to that of magnesia-doped hot-pressed silicon nitride at $1200^{\circ} \mathrm{C}$ for an applied stress of $350 \mathrm{MPa}$.

E. Y. Sun et al. $^{4)}$ reported that significant improvement in the R-curve behavior and the steady-state fracture toughness values was observed with a high $\mathrm{Y}_{2} \mathrm{O}_{3}: \mathrm{Al}_{2} \mathrm{O}_{3}$ ratio in the sintering additives. They also found that silicon nitride with high $\mathrm{Y}_{2} \mathrm{O}_{3}: \mathrm{Al}_{2} \mathrm{O}_{3}$ ratio such as $6.25: 1$ exhibited more extensive debonding at grain boundary interface, compared to that with low $\mathrm{Y}_{2} \mathrm{O}_{3}: \mathrm{Al}_{2} \mathrm{O}_{3}$ ratios such as $4.0: 2.8$ and $5.0: 2.0$, resulting in increased intergranular fracture toughness.

The objective of the present research is to develop the pressure-assisted master-sintering surface (PMSS) of silicon nitride with high $\mathrm{Y}_{2} \mathrm{O}_{3}: \mathrm{Al}_{2} \mathrm{O}_{3}$ ratio of $6.25: 1$. The PMSS is one of the hot pressing models recently developed by K. An and D. L. Johnson by extending the concept of the master sintering curve for pressureless sintering ${ }^{5)}$ in which the sintered density is a unique function of the integral value of a temperature function over time irrespective of the heating path.

\section{Experiments}

A dilatometer determined the linear shrinkage from the motion of the pressing ram during hot pressing.

High-purity $\alpha-\mathrm{Si}_{3} \mathrm{~N}_{4}$ powder $(0.8 \mu \mathrm{m}$ of diameter, E-10 grade, Ube Industries, Tokyo, Japan) was mixed with $6.25 \% \mathrm{Y}_{2} \mathrm{O}_{3}$ and $1 \% \mathrm{Al}_{2} \mathrm{O}_{3}$. Pellets $25.4 \mathrm{~mm}$ in diameter and approximately $2 \mathrm{~mm}$ thick were pressed at $300 \mathrm{MPa}$ without using binder.

Two different heating and pressure schedules were used. First, 27.6 MPa pressure was applied at room temperature and then the furnace was heated to $1800^{\circ} \mathrm{C}$ in separated runs at 0.083 and $0.167^{\circ} \mathrm{C} / \mathrm{s}$ heating rates.

Secondly, hot pressing using applied pressures from 6.9 to $34.5 \mathrm{MPa}$ were conducted. Pressure was applied at room temperature and a constant heating rate of $0.167^{\circ} \mathrm{C} / \mathrm{s}$ was maintained from room temperature to $1800^{\circ} \mathrm{C}$ without isothermal hold.

Microstructures were examined by scanning electron microscopy on fracture surfaces. Bulk and apparent densities as well as open and closed porosity levels were determined by the Archimedes method.

\section{Results and Discussion}

The master sintering curve (MSC) was derived from a combined stage sintering model ${ }^{6,7)}$ which includes both volume and grain-boundary diffusion mechanism. The instantaneous densification rate in the latter model is

$$
\frac{d \rho}{\rho d t}=\frac{3 \gamma \Omega}{k T}\left(\frac{\Gamma_{\mathrm{v}} D_{\mathrm{v}}}{G^{3}}+\frac{\Gamma_{\mathrm{b}} \delta D_{\mathrm{b}}}{G^{4}}\right) .
$$

Where $\gamma$ is the surface energy, $\Omega$ the atomic volume, $k$ the Boltsmann constant, $T$ the absolute temperature, $G$ the mean grain diameter, $D_{\mathrm{v}}$ and $D_{\mathrm{b}}$ the coefficients of volume and grain boundary diffusion, respectively and $\delta$ the width of the grain boundary. $\Gamma_{\mathrm{v}}$ and $\Gamma_{\mathrm{b}}$ are lumped scaling parameters.

This equation can be rearranged for either grain boundary or volume diffusion such that all terms that not explicitly functions of temperature are carried to the left hand side, and then integrated, as follows: 


$$
\frac{k}{\gamma \Omega D_{0}} \int_{\rho_{0}}^{\rho} \frac{G^{n}}{3 \rho \Gamma} d \rho=\int_{0}^{t} \frac{1}{T} \exp \left(-\frac{Q}{R T}\right) d t
$$

where $Q$ is the apparent activation energy, $D_{0}$ is the preexponential term for the diffusion coefficient, $R$ is the gas constant, and $n=3$ or 4 for volume or grain boundary diffusion, respectively. For the master sintering curve, the measured density is plotted as a function of the right term of eq. (2), hereafter denoted $\Theta$ (See eq. (3)). If a single mechanism is responsible for densification, the sintered density can be predicted from the curve irrespective of the heating path. ${ }^{5}$ )

$$
\Theta=\int_{0}^{t} \frac{1}{T} \exp \left(-\frac{Q}{R T}\right) d t
$$

The application of MSC using silicon nitride powder was made by comparing the density of the specimens hot pressed at $27.6 \mathrm{MPa}$ and heated to $1800^{\circ} \mathrm{C}$ in separated runs of 0.083 and $0.167^{\circ} \mathrm{C} / \mathrm{s}$ heating rates. The density as a function of temperature is shown in Fig. 1.

When the density was plotted as a logarithmic function of $\Theta$, where $\Theta$ was defined as eq. (3), the two data sets merged onto a single curve. That is a constant pressure trace on the PMSS (Fig. 2). The estimated activation energy was found to be $698 \mathrm{~kJ} / \mathrm{mol}$. This was in excellent agreement with the values in literature. ${ }^{8-10)}$

The effect of applied pressure on microstructure of silicon nitride from 6.9 to $34.5 \mathrm{MPa}$ was studied under equivalent heating schedule of $0.167^{\circ} \mathrm{C} / \mathrm{s}$ from room temperature to

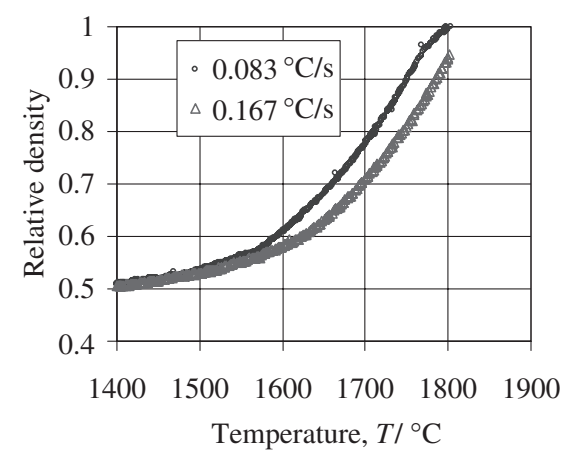

Fig. 1 Density as a function of hot pressing temperature at 27.6 MPa.

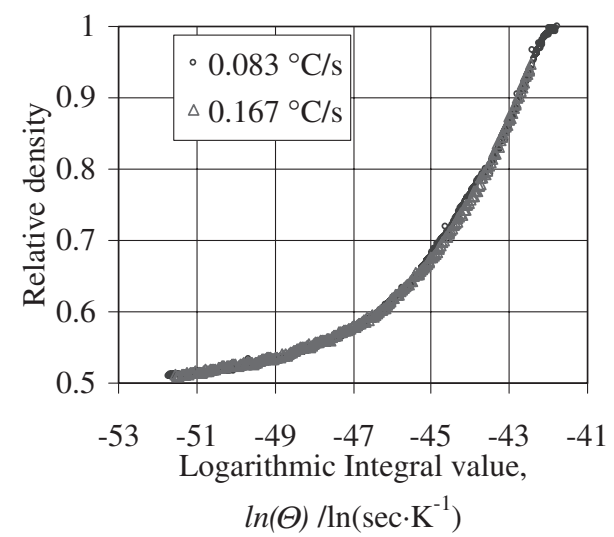

Fig. 2 Master sintering curve for data of Fig. 1.

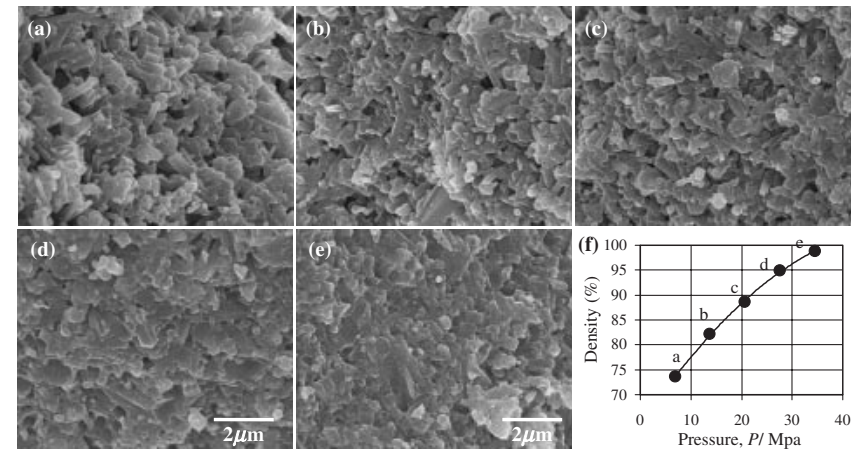

Fig. 3 Microstructural evolution with increasing pressure (a)-(e) from 6.9 to $34.5 \mathrm{MPa}$ and (f) their corresponding densities determined by Archimedes method.
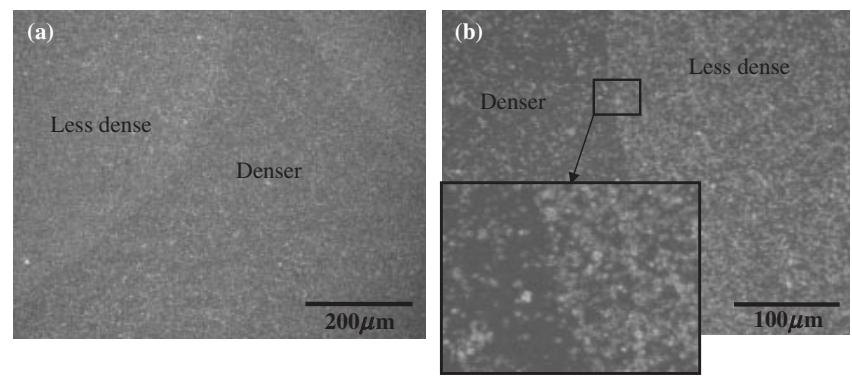

Fig. 4 SEM micrographs of polished surfaces. Specimens were made at (a) $13.8 \mathrm{MPa}$ and (b) $20.7 \mathrm{MPa}$.

$1800^{\circ} \mathrm{C}$ without isothermal heating. Figure 3(a)-(f) show microstructural evolution with increasing pressure as well as their corresponding densities determined by Archimedes method.

Polished surfaces of the specimens in Fig. 3(b) and (c) show non-homogeneous densification feature of silicon nitride, since the boundary between dark and bright regions corresponding to denser and less dense regions respectively were clearly observed throughout the surface as shown in Fig. 4(a) and (b). Less dense region containing more porosity seemed bright due to the fact that electrons of scanning electron microscopy scattered more at porosity which is not electrically conductive.

Phase transformation of $\alpha$ to $\beta$ phase was also observed while the initial powder was $\alpha$ phase. Figure 5(a) and (b) illustrate the X-ray diffraction patterns of the selected specimens made at $6.9 \mathrm{MPa}$ and $34.5 \mathrm{MPa}$. Almost entire peaks were identified as $\alpha$ and $\beta$ of silicon nitride. As the densification processed, the peaks from $\beta$ phase increased. Although the specimen achieved close to a full density as 98.8\% of theoretical, a certain amount of $\alpha$ phase still remained, but the exact amount is not available at this time. H. Suematsu et $a l^{2)}$ reported that the phase transformation significantly depends on the types and amount of additives. They observed that the $\alpha$ and $\beta$ phases coexist after annealing of $\alpha$ phase silicon nitride using $\mathrm{MgO}_{2} \cdot 3 \mathrm{Al}_{2} \mathrm{O}_{3}$ additives; furthermore, only the $\beta$ phase was found after annealing with $\mathrm{Y}_{2} \mathrm{O}_{3}$ additive. For the present study, the composition of additives were selected as $6.25 \% \mathrm{Y}_{2} \mathrm{O}_{3}$ and $1 \% \mathrm{Al}_{2} \mathrm{O}_{3}$ both of $\alpha$ and $\beta$ phases were observed after sintering, which is consistent with literature. $^{2)}$ 


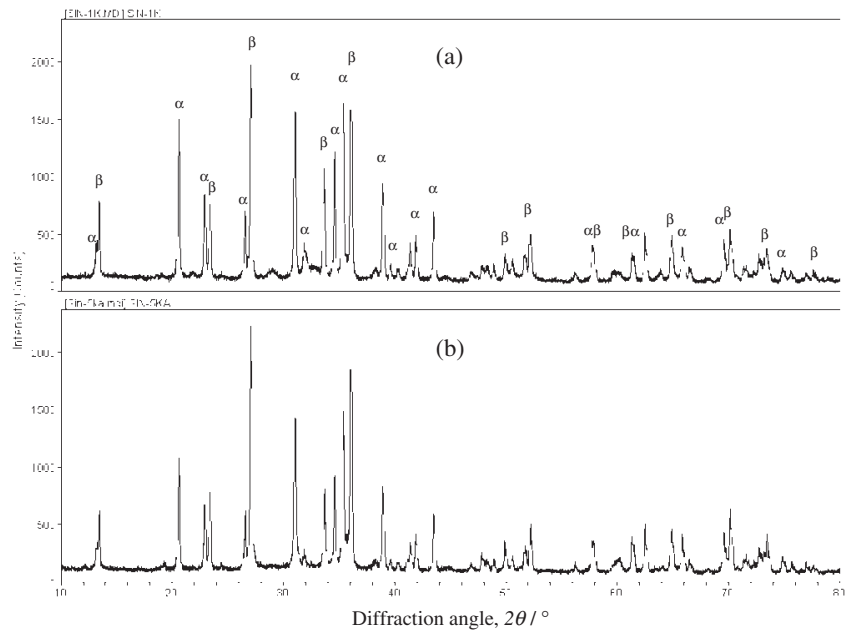

Fig. 5 Relative peak intensities of $\beta$ phase between specimens made at (a) 6.9 and (b) $34.5 \mathrm{MPa}$.

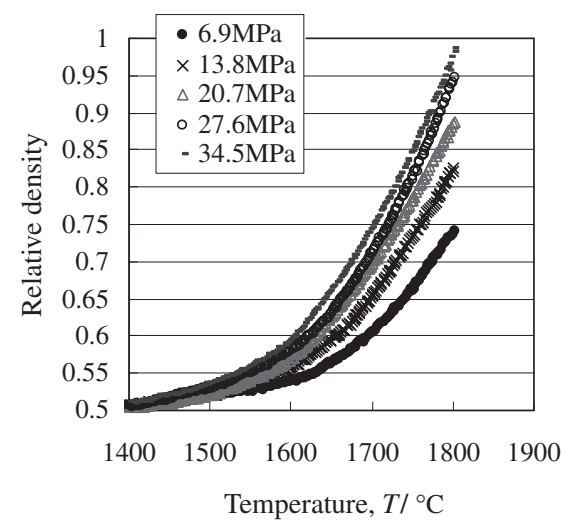

Fig. 6 Relative density versus temperature using a constant heating rate of $0.167^{\circ} \mathrm{C} / \mathrm{s}$ at varying applied pressure from 6.9 to $34.5 \mathrm{MPa}$.

The density as a function of temperature for $0.167^{\circ} \mathrm{C} / \mathrm{s}$ heating rate using constant applied pressures from 6.9 to 34.5 $\mathrm{MPa}$ is given in Fig. 6. Pressures are, from right to left, $6.9,13.8,20.7,27.6$ and $34.5 \mathrm{MPa}$. Figure 7 shows the constant pressure contours of the PMSS constructed from the densification data in Fig. 6. Pressures are, again from right to left, 6.9, 13.8, 20.7, 27.6 and 34.5 MPa. To develop other views, points of time-temperature integral were picked at $0.65,0.7, \ldots 0.95$ for each of the constant pressure curves, and multiple regression analysis was done to obtain an empirical model of PMSS. The resulting surface is shown in Fig. 8. It now is possible to predict the density of a specimen hot pressed at any pressure from 0 to $34.5 \mathrm{MPa}$ if the temperature-time trajectory is known.

\section{Conclusions}

The application of MSC using silicon nitride powder was made by comparing the density of the specimens hot pressed at $27.6 \mathrm{MPa}$ and heated to $1800^{\circ} \mathrm{C}$ in separated runs of 0.083 and $0.167^{\circ} \mathrm{C} / \mathrm{s}$ heating rates. Silicon nitride was mixed with sintering additives of $6.25 \% \mathrm{Y}_{2} \mathrm{O}_{3}$ and $1 \% \mathrm{Al}_{2} \mathrm{O}_{3}$. When the density was plotted as a logarithmic function of $\Theta$, the two data sets merged onto a single curve, in which the activation

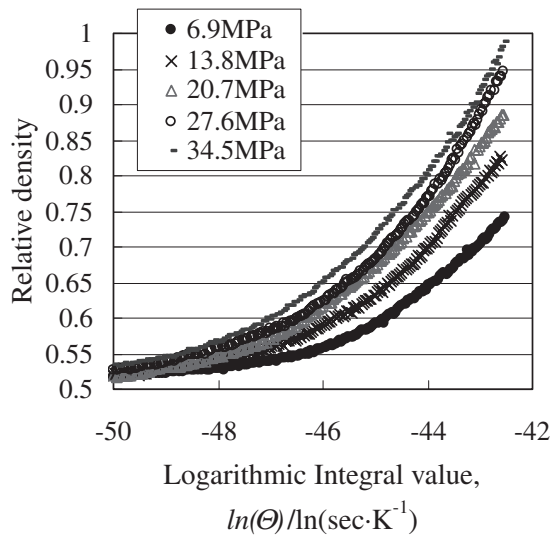

Fig. 7 Constant pressure contours of the PMSS constructed using the data of Fig. 6.

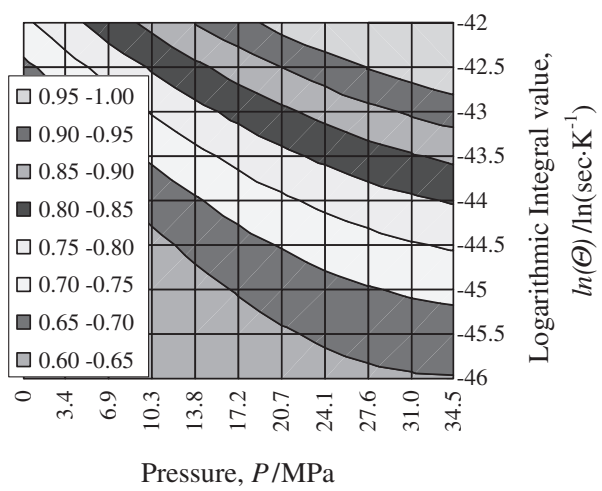

Fig. 8 Constant density contour plot of the PMSS.

energy was estimated as $698 \mathrm{~kJ} / \mathrm{mol}$. Phase transformation of $\alpha$ to $\beta$ phase was also observed while the initial powder was $\alpha$ phase. As the densification processed, the peaks from $\beta$ phase increased.

The PMSS of silicon nitride from 0 to $34.5 \mathrm{MPa}$ pressure was constructed, which enables the prediction of the density if the temperature-time trajectory is known. It also can be used to specify the heating schedule required to achieve a target density at a given pressure.

\section{REFERENCES}

1) H. Knoch and G. E. Gazza: Ceramurgia Int. 6 (1980) 51-66.

2) H. Suematsu, M. Mitomo, T. E. Mitchell, J. J. Petrovic, O. Fukunaga and N. Ohashi: J. Am. Ceram. Soc. 80 (1997) 651.

3) S. M. Wiederhorn and N. J. Tighe: J. Am. Ceram. Soc. 66 (1983) 884-889.

4) E. Y. Sun, P. F. Becher, K. P. Plucknett, C. H. Hsueh, K. B. Alexander and S. B. Waters: J. Am. Ceram. Soc. 81 (1998) 2831-2840.

5) H. Su and D. L. Johnson: J. Am. Ceram. Soc. 79 (1996) 3211-3217.

6) J. D. Hansen, R. P. Rusin, M. Teng and D. L. Johnson: J. Am. Ceram. Soc. 75 (1992) 1129-1135.

7) D. L. Johnson, R. P. Rusin and J. D. Hansen: Sintering-Advances in Powder Metallurgy and Particulate Materials Vol. 3, (Metal Powder Industries Foundation, Princeton, NJ 1992) pp. 17-24.

8) G. R. Terwilliger and F. F. Lange: J. Am. Ceram. Soc. 57 (1974) 25-29.

9) R. Raj and P. E. D. Morgan: J. Am. Ceram. Soc. (1981) C-143.

10) L. J. Bowen, R. J. Weston, T. G. Carruthers and R. J. Brook: J. Mater. Sci. 13 (1978) 341-350. 